\title{
Infrared remote sensing of Earth degassing - Ground study
}

\author{
Volker Tank $\left({ }^{1}\right)$, Hardy Pfanz $\left({ }^{2}\right)$, Hans Gemperlein $\left({ }^{1}\right)$ and Peter Strobl $\left({ }^{1}\right)$ \\ $\left({ }^{1}\right)$ Remote Sensing Technology Institute, German Aerospace Center, Wessling, Germany \\ ${ }^{(2)}$ Lehrstuhl für Angewandte Botanik/Ökophysiologie, Universität Duisburg-Essen, Germany
}

\begin{abstract}
Geodynamical processes e.g., volcanoes, often cause degassing at the Earth surface. The geogas emanates via mineral springs, water mofettes, or dry mofettes. It is assumed that the emerging gas influences the temperature of the spring or mofette water, respectively and the surface temperature of the soil at and around the dry gas vents. This causes a thermal anomaly in comparison to the close vicinity. Under specific conditions this effect should be extractable from remotely acquired infrared images allowing detection, mapping and monitoring of gas vents/springs within large areas and short times. This article describes preparatory investigations for which emanating Earth gas was simulated by leading compressed air into the ground and releasing it in some depth via a metal lance. The thermal effect at the surface was observed from a nearby thermovision camera in summer and winter under varying meteorological conditions. A procedure was developed to reliably identify gas release areas within the recorded thermal images of the scene. The investigations are aiming at studies to be performed later in the Western Bohemia (Czech Republic) earthquake swarm region where especially $\mathrm{CO}_{2}$ of magmatic origin from European SubContinental Mantle (ESCM) emanates.
\end{abstract}

Key words mofettes - thermography - remote sensing - swarm earthquakes - $\mathrm{CO}_{2}$-gas emission

\section{Introduction}

From the geo-scientific point of view the Earth crust and upper mantle below West Bohemia and the Vogtland are unique due to periodically recurring swarm earthquakes and to the proven combination of seismic activity and high flux gas emanation in extended areas. The gas originates from an active magmatic reservoir within the sub-continental upper mantle. Most probably active faults which penetrate the crust act as transport channels for the mantle fluids.

Mailing address: Dr. Volker Tank, Remote Sensing Technology Institute, German Aerospace Center, DLR, Oberpfaffenhofen, P.O. Box 1116, D-82230 Wessling, Germany; e-mail: Volker.Tank@dlr.de
Whereas the extraordinary seismic characteristics of the region have long been known the knowledge of the extended gas emanations is new (Weinlich et al., 1999) and gives reason to consider the region an international reference area for investigations of the interrelation of swarm earthquakes and fluid dynamics. To date the cause of the crust behaviour «swarm earthquake» is not well understood. A scientific solution requires the investigation of the whole area and its vicinity.

Available data have to be considered and new data have to be gathered. A survey and mapping of the majority of gas rich springs and dry gas vents is highly desirable to establish a solid basis for further investigations like the local interrelation of geological faults and gas vents, the total gas flux rate and its variability, the interrelation of seismic activity and gas flux rate, and the like. This will contribute to an understanding of the fluid dynamic, tectonic and structural geology of the region. Attempts were made earlier to detect emitted gases of known 
vents by means of airborne or spaceborne remote sensing instrumentation (de Jong and Chrien, 1996). Complementary to this a method is soon to be established to allow for the detection of gas emitting springs and vents in a wide area. The approach proposed and described here assumes the application of airborne infrared imaging instrumentation to detect soil and water surface thermal anomalies which are caused by emanating gas. It assumes that the gas temperature is relatively constant over time compared to the surface temperature which undergoes fast diurnal and wide seasonal changes and strongly depends on the specific weather. Conditions can be expected under which due to the thermal inertia of soil and water the influence on the emanating gas on the surface temperature of the water and around the dry gas vents will be pronounced. These conditions are to be identified and the flight survey to be performed accordingly. In preparation of systematic investigations in West Bohemia a simple experiment has been performed to achieve the first qualitative impressions of the thermal effect of gas emanating the earth surface.

In parallel eco-physiological investigations have been performed to determine the influence of the escaping $\mathrm{CO}_{2}$-gas on the plant communities growing within the varying $\mathrm{CO}_{2}$ concentrations within the mofette fields (Pfanz et al., 2004). The combination of remote sensing and plant physiology to detect geogas emanations is a new approach to develop remote detection and monitoring methods for earth degassing locations.

\section{Mineral springs and mofettes in West Bohemia}

The region of interest is located at and around the crossing of the Eger rift and the Mariánské Lázně Fault. Up to 140 mineral springs and a number of 50-500 mofettes (dry gas vents, sometimes filled with rain water or near surface ground water) are described to be located at the intersection of these fault zones within an area of 1500 $\mathrm{km}^{2}$. It is especially difficult to detect dry vents as can be deduced from the reported uncertainty of $50-500$ vents. They are not associated with the certainly conspicuous water. The gas flux rate covers a wide range between less than $1 \mathrm{l} / \mathrm{h}$ and more than 85000 l/h (Weinlich et al., 1998). The whole area has not been investigated yet. Hence more mofettes have been found in field experiments (Bankwitz et al., 2001) and searches. Many are discovered because they form shallow dips free of vegetation. Frequently suffocated mammals or birds can be found on their ground (fig. 1). The size varies between a few $\mathrm{dm}^{2}$ and several $\mathrm{m}^{2}$. Searching for them however consumes an extraordinary amount of time in pathless and sometimes dangerous swampy terrain.

Numerous gas-rich springs and mofettes (fig. 2) have been mapped, many have been investigated in great detail (Weinlich et al., 1999). The

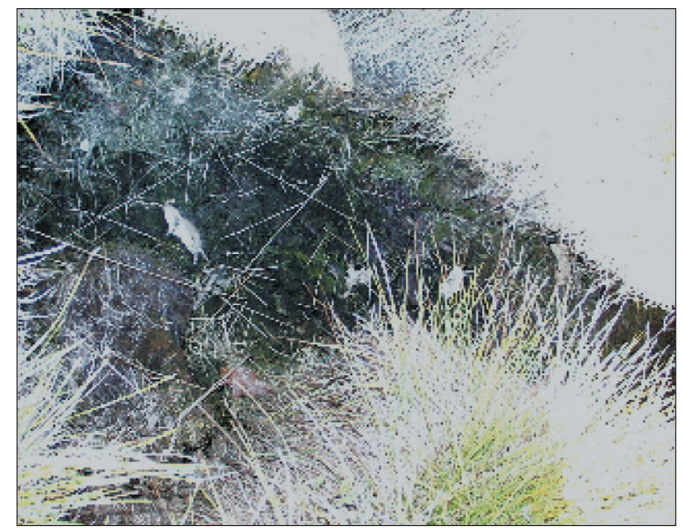

Fig. 1. Suffocated mouse inside dry vent.

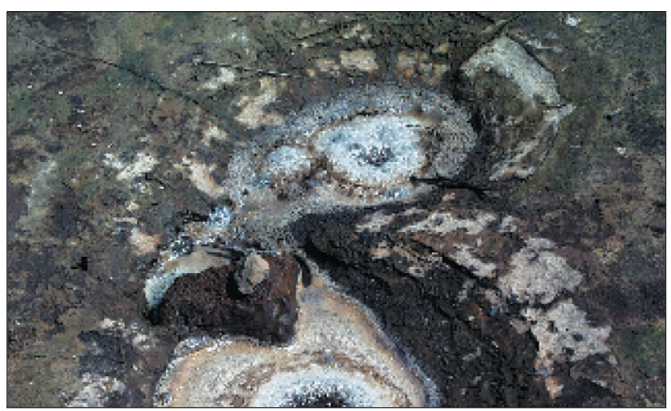

Fig. 2. Mofettes in Soos. 
water of the springs carries dissolved minerals, $\mathrm{CO}_{2}$ (among other gases) and hydrocarbon $\mathrm{HCO}_{3}^{-}$from some depth and horizontally over some hundred or thousand meters to the surface. The lower surface pressure causes $\mathrm{CO}_{2}$ to dissolve and escape as free gas according to its partial pressure. The total amount of released gas depends on the amount solved, the pressure difference, the water temperature and the water flux rate. In mofettes the water and/or soil are flown through by the emerging gas, mainly $\mathrm{CO}_{2}$ that originates from the upper mantle reservoir.

\section{Thermal behaviour of mineral springs and mofettes}

The question to be investigated is if the thermal signature of the three different types of $\mathrm{CO}_{2}$ emanations (mineral spring, water mofette, dry mofette) can be utilised as an indicator for the existence of the gas and furthermore if it contains information on the gas flux. Finally, can the gas flux information be extracted from the thermal signature? Only the first question will be considered here.

For mineral springs because of the low thermal capacity of gas, the long way to the surface and the long time associated with the flow to the surface of several months (Weise et al., $2001)$ it is very unlikely that the water temper- ature at the surface can be used as an obvious indicator for the presence of gas. It is rather determined by the thermal conditions on the way up than by the gas temperature at the origin.

The water temperature of water mofettes depends on environmental conditions, the amount of water and the temperature and flux of the gas flowing through. Similarly, the soil temperature of dry mofettes is determined by the gas and the soil parameters (moisture, etc.). The gas temperature is determined by the conditions at its origin and on the way to the surface. If the flux is large enough in comparison with the amount of water it can be expected that the water temperature's seasonal variations are altered since the gas temperature undergoes much fewer seasonal changes. It will be difficult to discriminate the temperature effect of the gas, however, because in general there is no reference object available. Such should be a water reservoir of the same size, volume and structure as the mofette. It should be at a very close location undergoing the same environmental influences but lacking the gas flowing through it. These will be very rarely if at all available. It has not been investigated so far, if the deduction of the gas flux from the mofette water temperature is possible. Figure 3 shows the course of the water temperature of two mofettes and two springs over the time period from May 2000 to December 2002. The data were received from $\mathrm{H}$. Kämpf in a private communication.

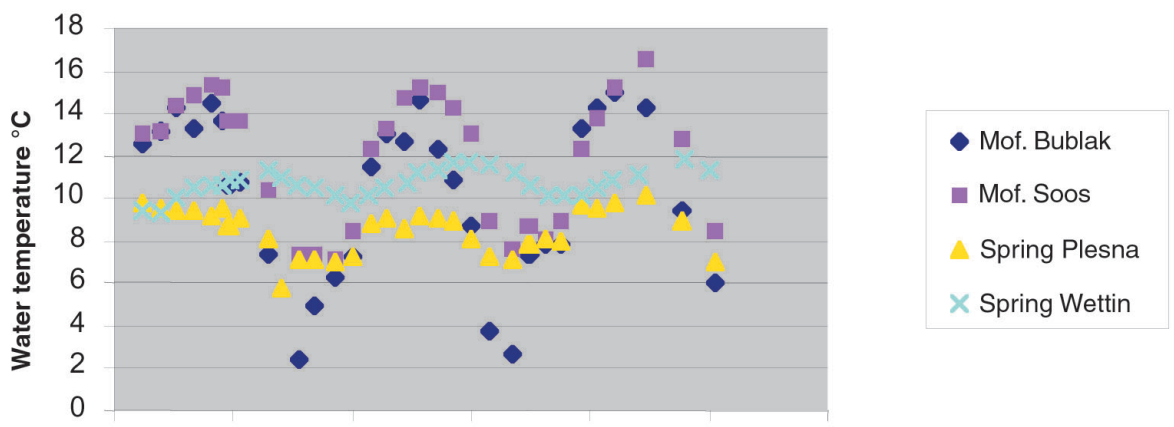

15.03.00 01.10.00 19.04.01 05.11.01 24.05.02 10.12.02 28.06.03

Date

Fig. 3. Water temperature of two mofettes and two springs during 32 months. 
Figure 3 demonstrates the influence of the seasonal environmental temperature course on the water temperature of water mofettes and springs. Mofettes (standing water) are more exposed to seasonal weather than flowing spring water, hence their temperature variations are stronger. Tubing and housing of a spring cause additional thermal effects as can be seen in the comparison of the temperature measurements of the Wettin (tubed and housed) and Plesna springs.

As a conspicuous exception from the above described typical thermal behaviour very shortterm mofette water and soil temperature variations during the 2000 second main swarm-quake period have been reported but not explained satisfactorily to date (Koch et al., 2003).

Regarding dry mofettes it can be stated that the surface temperature of bare or vegetationcovered soil surfaces is primarily determined by the soil properties (thermal conductivity/capacity, moisture, radiative absorbance, etc.), the impinging radiation (sun), and the weather (air temperature, wind, clouds, etc.). Small scale areas of soil which can be considered homogenous with respect to the parameters of influence will therefore adopt a fairly uniform surface temperature. Any disturbance of the homogeneity will cause thermal anomalies of the soil surface. These can be detected if they are regional with respect to the otherwise homogeneous area. This is the case with many of the dry mofettes. The mofette gas thermal forcing is superimposed on all other thermal effects and restricted to the close vicinity of the gas outlet. Depending on the diurnal and seasonal course and the actual weather pattern the thermal gas imprint and hence the detection conditions will vary significantly. The most favourable conditions have to be found in field experiments.

It can be concluded that of all three types of gas emanations (spring, water mofette, dry mofette), the dry mofette is most likely to allow the remote detection of gas induced thermal anomalies through the application of infrared sensors. Hence it is expected to detect dry mofettes directly, whereas mineral springs and water mofettes have to be confirmed following the detection of surface water.

\section{Experimental set-up}

In preparation of planned airborne field campaigns in West Bohemia a simple small experiment was set up at the DLR Remote Sensing Technology Institute (Wessling) to gain a first insight into the thermal effect of emanating gas on the soil surface. As a test area a mowed meadow in front of a laboratory was chosen. The emerging gas was simulated by releasing compressed air in about $20 \mathrm{~cm}$ depth in the ground of the meadow. The air was taken from the common institute's supply for the technical workshops (central compressor station). The air was guided through a thermally insulated hose to a metal lance. The lance consists of a pipe with a cone end, containing three $6 \mathrm{~mm}$ diameter holes to release the air. The lance was obliquely driven into the ground, such that the cone end was about 20 $\mathrm{cm}$ below the surface. Gas flow was dosed using a simple ball valve. At the time of these experiments no flow meter was available. The flow can be estimated to have been between $100 \mathrm{l} / \mathrm{min}$ and $150 \mathrm{l} / \mathrm{min}$. This is based on flow measurements which were performed at a later date, when the valve was approximately at the same setting. Figure 4 shows the gas injection equipment.

Thermocouple sensors were used to determine the soil temperatures at the gas outlet in the ground resembling the temperature of the gas at the time of release into the soil and at an offside location for comparison. Soil surface emitted infrared radiation distribution was observed by an infrared camera AGEMA 570 installed inside the laboratory at a distance of approximately $4 \mathrm{~m}$ from the lance. The system detector is an uncooled micro-bolometer array of vanadium oxide, containing $320 \times 240$ pixels. Its spectral range is $7.5-13 \mu \mathrm{m}$ wavelength. The field of view of $\mathrm{FOV}=24^{\circ} \times 18^{\circ}$ (total observation angle horizontal $\times$ vertical) results in a spatial resolution of $1.3 \mathrm{mrad}$. The system converts detected radiation into equivalent black body temperature which is displayed via colour encoding. The temperature resolution is $\mathrm{NE} \Delta T=0.15 \mathrm{~K}$ at $300 \mathrm{~K}$. NE $\Delta T$, Noise Equivalent Temperature Difference resembles the smallest temperature difference of 


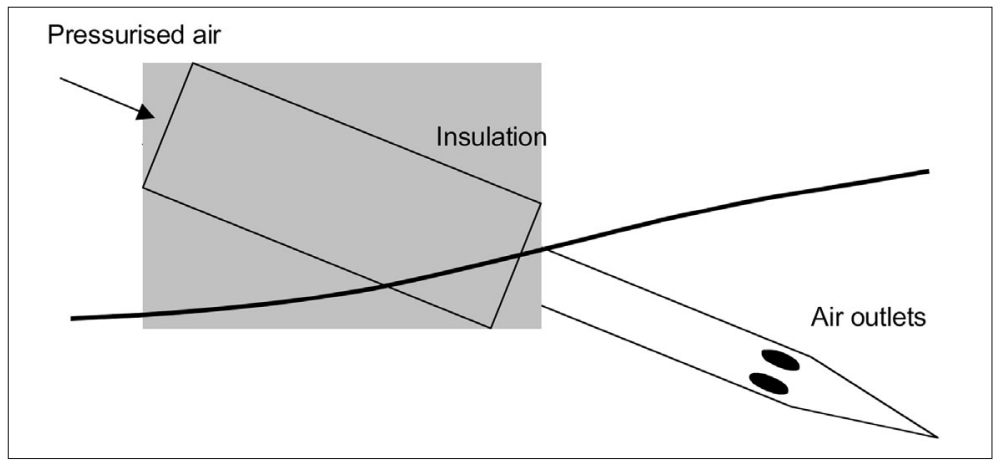

Fig. 4. Drawing of lance, cone end with holes and insulated air inlet.

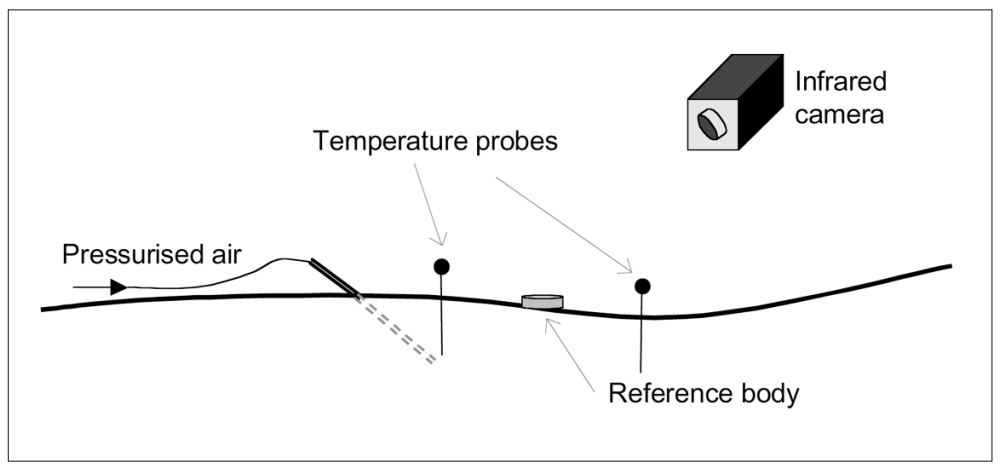

Fig. 5. Schematic view of experiment setup: lance; two temperature sensors, one at the air outlet, the other offside, tips are $10 \mathrm{~cm}$ below the surface; the infrared camera is approximately $5 \mathrm{~m}$ away from the test field.

two different picture elements in the observed scene that can be distinguished, hence it resembles the camera's accuracy. The precision of an infrared camera measurement depends on the quality of its calibration, the knowledge of the emissivity of the observed object and the ambient radiation reflected at the object, as well as atmospheric attenuation effects and their correction. At this stage of the work the feasibility of remote sensing is investigated therefore temperature differences are of prime interest rather than precise temperature data. Thus the internal camera calibration is considered sufficient. Measurements (infrared images) of the scene were taken through the open laboratory win- dow. Schematic drawings show the experimental set-up in fig. 5 .

\section{Experiments and Results}

\subsection{Investigations during summer}

Experiments were performed on 13th August 2002 beginning at 09:00 $\mathrm{h}$ when the gas flow was turned on. Over several hours the ground surface temperature was periodically monitored with the infrared camera. Three of the recorded images are shown in fig. 6 . A fourth image in fig. 6 contains the outlines of three areas: grass back- 
ground, Ex1 and Ex2. From these sections the mean temperatures of background, exposed region 1 and exposed region 2 were derived.

At 09:00 $\mathrm{h}$ when the experiment area was fully shaded by a large building the surface temperature of the whole scene is fairly homogeneous and around $13^{\circ} \mathrm{C}$ to $14^{\circ} \mathrm{C}$ as can be deduced from the top image in fig. 6. At the same time both the thermocouple sensors (at the gas outlet and offside) determine a soil temperature of $18^{\circ} \mathrm{C}$ at a depth of approximately $20 \mathrm{~cm}$ below the surface.

About two hours later the soil surface temperature above the lance's gas outlet begins to differ from the surrounding.

At 11:30 h the effect is well pronounced as the middle image of fig. 6 reveals. The area had been exposed to sunshine but then clouds covered the sun and had been shading the area for a while. Therefore the temperature of the surrounding of the gas outlet is still (better: again) homogeneous and higher: around $17^{\circ} \mathrm{C}$, compared to $13^{\circ} \mathrm{C}$ to $14^{\circ} \mathrm{C}$ at 09:00 h. At the two distinct spots of the middle image, recognised as gas outlet areas, the soil surface temperature is between $11^{\circ} \mathrm{C}$ and $12^{\circ} \mathrm{C}$. Hence the emanating gas cools the surface. This is confirmed through the thermocouple sensors $20 \mathrm{~cm}$ deep in the soil: the one at the gas outlet reads $13^{\circ} \mathrm{C}$, the offside one still reads $18^{\circ} \mathrm{C}$. From these measurements it can be concluded that at the gas outlet soil and gas temperatures and thermal characteristics result in a equilibrium temperature of about $13^{\circ} \mathrm{C}$. These temperatures do not change after throughout the experiments which confirms stable conditions at a depth of 20 $\mathrm{cm}$ (gas outlet stays at $13^{\circ} \mathrm{C}$, the offside region at
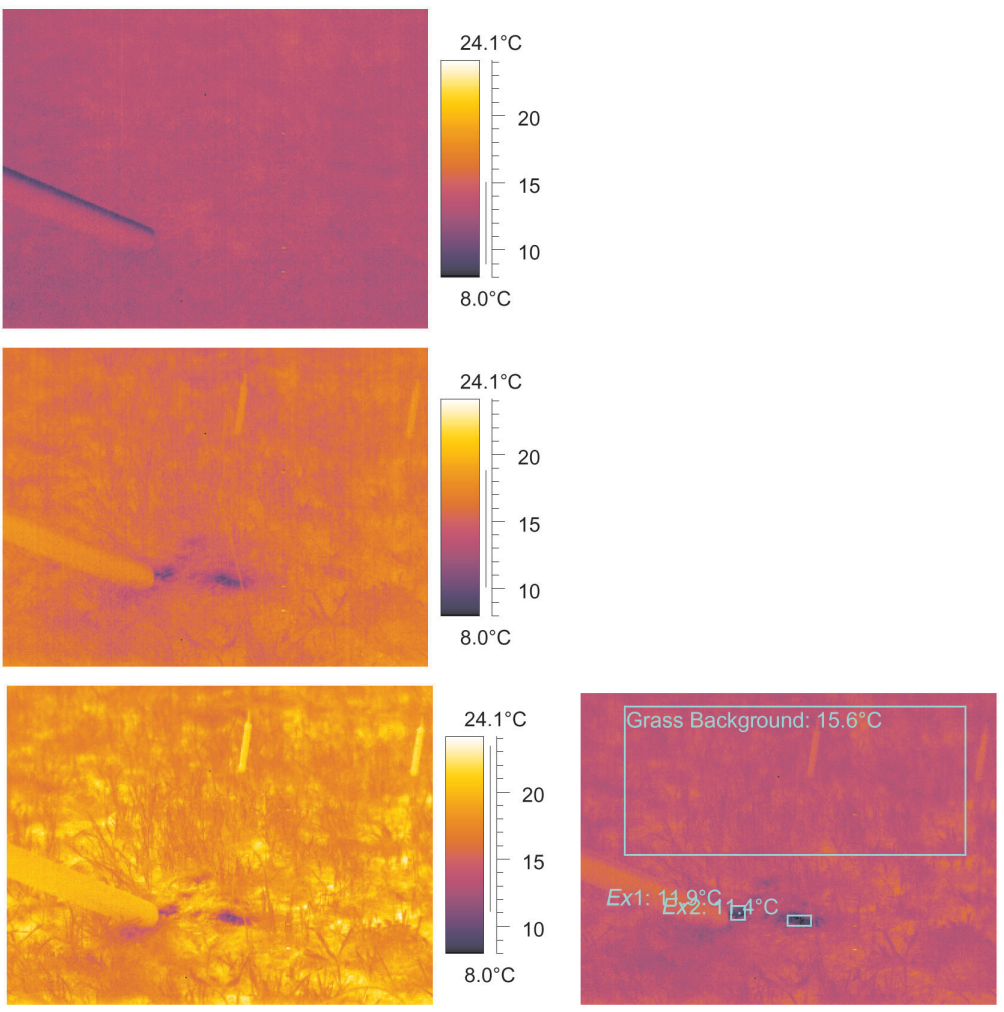

Fig. 6. Temperature distribution at gas release area, top at 09:00 h, middle at 11:30 h, bottom at 12:05 h, right image shows areas outlined from which mean temperatures were derived. 

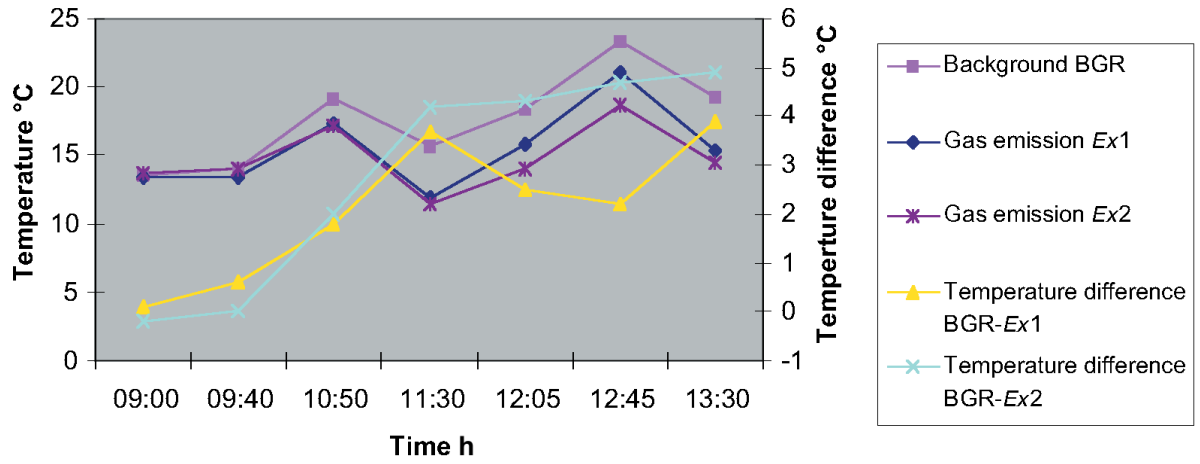

Fig. 7. Temperatures and temperature differences as function of time.

$18^{\circ} \mathrm{C}$ ). Thus a true mofette is quite well simulated insofar as a constant gas flow of constant temperature over a longer time will result in a constant equilibrium temperature of the soil where the gas is seeping through for a given depth. On the other hand, at a certain depth below the surface the soil temperature is not influenced by diurnal environmental temperature changes but by seasonal alterations only. For the given conditions one would expect the surface temperature derived from the camera measurement to be higher than the temperature at the gas outlet at $20 \mathrm{~cm}$ depth. This is not the case, however. The reasons for this are the limited measurement precision of the IR camera (surface) and the thermocouple sensors $(20 \mathrm{~cm}$ depth). As stated above, precision is not of main interest at this stage, hence precise calibration of the camera and consideration of environmental influences on the radiation measurements have been omitted.

The bottom image of fig. 6 was taken at 12:05 $\mathrm{h}$, when the area had been exposed to direct sunshine for about $30 \mathrm{~min}$. The area is now thermally inhomogeneous: spots on the soil have taken a temperature up to $24^{\circ} \mathrm{C}$ and $25^{\circ} \mathrm{C}$, whereas the grass temperature is as low as about $16^{\circ} \mathrm{C}$, the mean is $18.2^{\circ} \mathrm{C}$. The surface temperature at the two gas outlets is $14^{\circ} \mathrm{C}$ and $15.4^{\circ} \mathrm{C}$. The subsurface sensors show the same reading as before: $13^{\circ} \mathrm{C}$ and $18^{\circ} \mathrm{C}$.

When comparing the mean surface temperatures of the grass background and the gas emission regions over time, as shown in fig. 7 , it be- comes obvious that all surfaces are influenced by the amount of impinging sun's radiation. The ups and downs of the temperatures are associated with sunny and cloudy periods respectively. The temperature differences of background and gas emission regions, also shown in fig. 7 for the two gas emission areas Ex1 and Ex2 and the grass background area which are marked and denoted in fig. 6, vary depending on sunshine or cloudiness (the term «grass background» denotes an area not influenced by emerging gas). They do not reach a constant value. For the smaller gas emission area Ex 1 the temperature difference to the grass background decreases during sunny periods and increases during shady ones. The difference to the grass background for the larger area $E x 2$, obviously associated with a higher gas flux rate, is much less influenced by sun or clouds. Two hours after the experiment was started for the two regions Ex1 and Ex2 the difference is about $2^{\circ} \mathrm{C}$, from then on it stays above and reaches as much as $5^{\circ} \mathrm{C}$.

\subsection{Investigations during winter}

In order to better understand the thermal behaviour of the earth surface influenced by gas emanations infrared camera measurements were also conducted during winter conditions. Furthermore the experiments aim at the development of a procedure to reliably identify and localise gas emanations on the basis of in- 

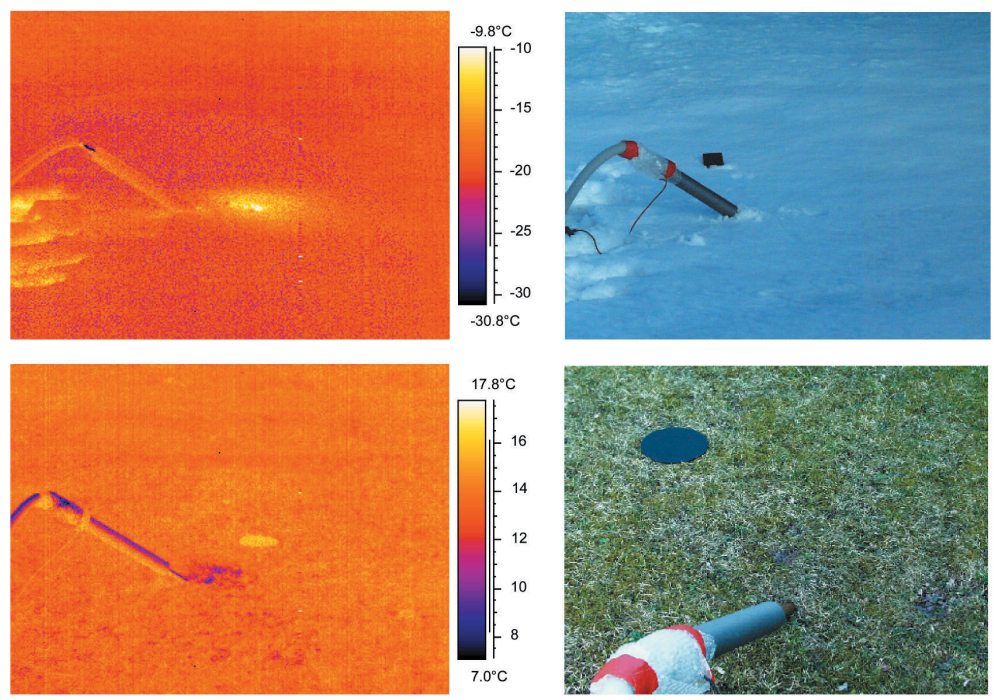

Fig. 8. Temperature distribution at gas release in snow covered terrain and after snowmelt.
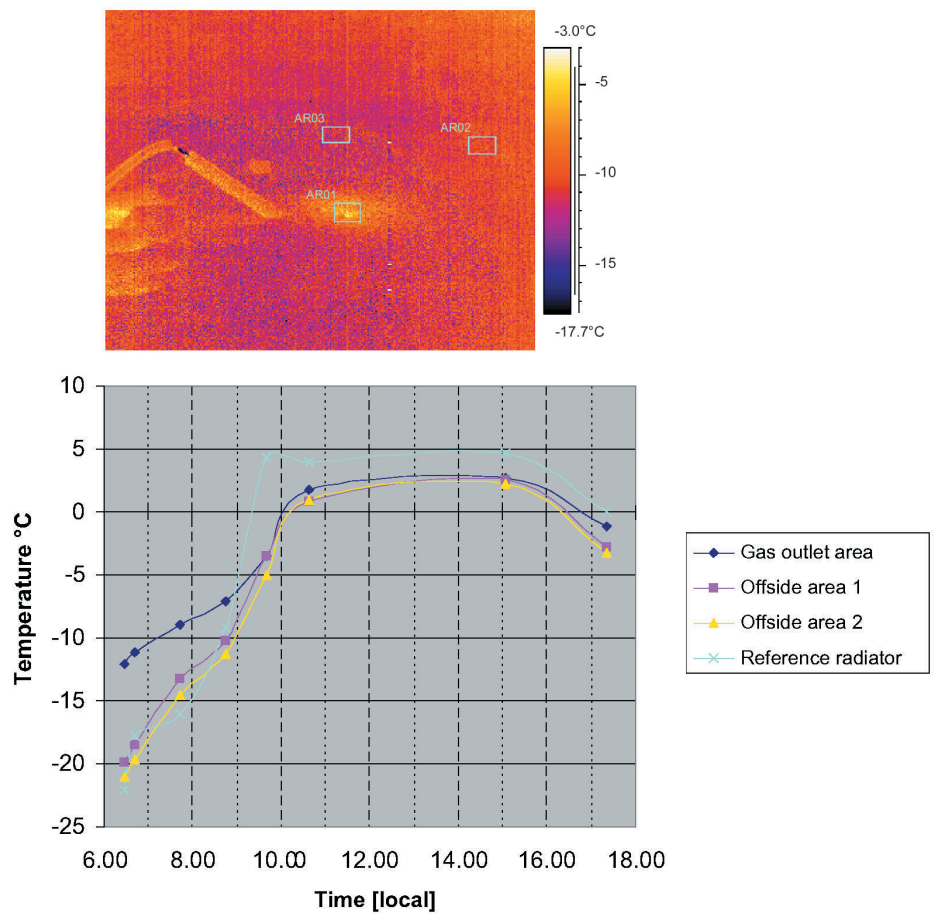

Fig. 9. Temperatures as function of time during 20th February 2003 of snow scene above; gas outlet and two offside areas are marked, reference radiator is visible as warm rectangular spot above middle of lance. 
frared remote sensing data. Figure 8 shows thermal images and photos of the gas release area covered by snow and after snow melt in February 2003. Top pictures reveal the gas warming up the snow, bottom pictures the gas cooling the grassy soil. For calibration purposes reference radiators are placed on the snow/ground. These consist of metal plates coated with $3 \mathrm{M}$ (registered trade mark) Velvet Coating of high spectral emissivity in the infrared spectral range. On 20th February 2003 nine measurements were recorded between 06:27 am and 05:21 pm in different time intervals. Figure 9 shows one of the images in which areas AR01 (gas outlet), AR02 (snow offside area 1), and AR03 (snow offside area 2 ) are marked. Furthermore the reference radiator can be identified above the lance. The average temperatures inside these three areas and of the reference radiator have been calculated from the images and plotted versus time in the diagram of fig. 9. This diagram reveals various processes during the day which can be explained as follows. The explanations assume a spectral emissivity of snow of $\varepsilon \approx 0.95$ in the spectral range of the IR-camera from $7.5 \mu \mathrm{m}<$ $<\lambda<13.5 \mu \mathrm{m}$ (Wolfe et al., 1989). The snow layer is about $15 \mathrm{~cm}$ thick. At the snow-soil boundary layer the temperature is $0^{\circ} \mathrm{C}$. Very early in the morning under clear sky the temperature of snow is $-20^{\circ} \mathrm{C}$, that of the reference radiator about $-22^{\circ} \mathrm{C}$, whereas the snow at the gas outlet area is about $-12^{\circ} \mathrm{C}$. The reference radiator is coldest because due to its very high spectral emissivity of $\varepsilon>0.98$ it radiates most energy of all objects of the scene into the clear sky and space. Within the gas outlet area the snow is heated by the gas which seeps through the soil underneath and then through the snow. Within a few hours temperatures rise and this proceeds more slowly for the gas outlet area than for the others. This first phase of warming up ends around 8:30 h when snow and reference radiator reach the same temperature of $-10^{\circ} \mathrm{C}$. At the beginning between $6: 00 \mathrm{~h}$ and $6: 30 \mathrm{~h}$ the temperature increase occurs in a straight line for all objects of the scene. It is caused by increasing skylight prior to sunrise. The rate of temperature change (temperature difference per unit time) is highest for the reference plate (due to its high spectral absorption in the visible spectral range), lower for the offside snow areas (due to the fact the spectral reflectivity of snow is high in the visible spectral range), and lowest for the gas release area (due to the compensating effect of the gas). After 6:30 dense fog accumulated above the scene causing the temperatures to increase more slowly. Less light is absorbed by the surfaces, the temperature change rate of the reference radiator drops most since it was the highest before. At about 8:00 h direct sunlight radiates onto the scene. Until 10:00 $\mathrm{h}$ all temperatures rise to a peak level fast and steadily. At the beginning the temperature change rate of the gas release area is smallest and adapts to the offside snow areas' rate as soon as the temperature of the three areas are the same, about $-4^{\circ} \mathrm{C}$ at 09:36 $\mathrm{h}$. The rate of the reference radiator is higher as is its peak temperature. Fog again floods the scene causing a balance between absorbed and emitted energy and fairly constant temperature for all objects. At about 15:00 h the sun is shaded off and all temperatures decrease. It is obvious that among all the change rate of the gas release area is the smallest. The conclusion of the observations is that gas seeping through the soil has the effect of thermal dampening the externally induced temperature changes at the surface. It reduces the temperature change rate under certain thermal environment conditions.

\section{Detection procedure}

The thermal dampening of emerging gas can be utilised for the detection of mofettes by infrared remote sensing in the following way, which can be called «change rate detection procedure». Two or more IR images of the scene are recorded at two or more different points time. These points of time are selected to provide well distinguished environmental conditions between which there is a pronounced thermal effect on the observed scene (temperature increase or decrease, for example night, morning, day). The IR images are then subtracted from one another. Prerequisite to this is the exact geometrical matching of both 
images which can be assured by standard image processing procedures. An image of temperature differences will result. By setting thresholds for the temperature difference in this image areas of different temperature change rate will be identified. Low change rates indicate damping effects the cause of which might be emerging earth gas. To exclude artefacts caused by shadowed areas, vegetation and the like images of the scene in the visible spectral range (colour photo) are taken in parallel to the thermal images. A crosscheck of thermal image and photo is done to verify the result of the change rate detection procedure. If necessary an in situ verification can be performed. An example of the application of the change rate detection procedure on the winter experiments is shown in fig. 10, the accompanying photo reveals that compressed snow (footsteps at the left side) causes thermal dampening, as does the shadow of the lance and the shadowed part of the lance itself.

Figure 11 shows the application of the change rate detection procedure to a real mofette location in the forest of Podhorny Vrch, Czech Republic. In fig. 12 the location is found free of vegetation, the soil is of peat appearance, covered with dry spruce needles, twigs and small branches. At some spots gas release can be heard, its coolness felt with the hand, it is visible by extraordinary grey coloured twigs within the otherwise brown surface cover. Two thermal images were taken at 18:18 $\mathrm{h}$ when the scene was shaded by a cloud and at 18:26 h
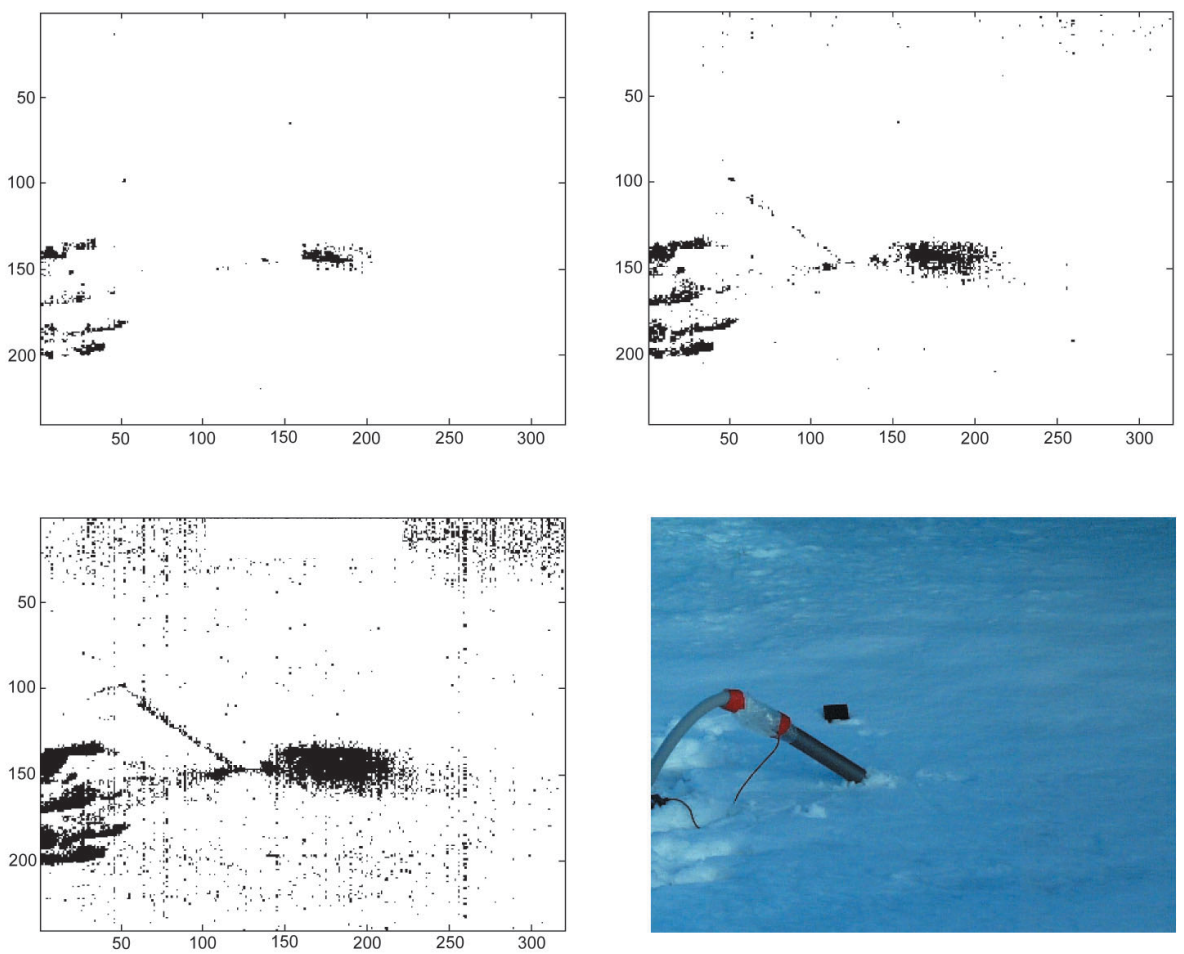

Fig. 10. Temperature difference $\Delta T$ of the snow scene recorded at two different times on 20th February 2003, at 06:27 $\mathrm{h}$ and at 06:41 $\mathrm{h}$. Threshold is $\Delta T<2 \mathrm{~K} ;<3 \mathrm{~K} ;<4 \mathrm{~K} ;<5 \mathrm{~K}$ from top left to bottom right. Several areas of low $\Delta T$ detected. Colour photo of snow scene reveals mechanically undisturbed snow at gas outlet and compressed snow left of it (foot prints). 

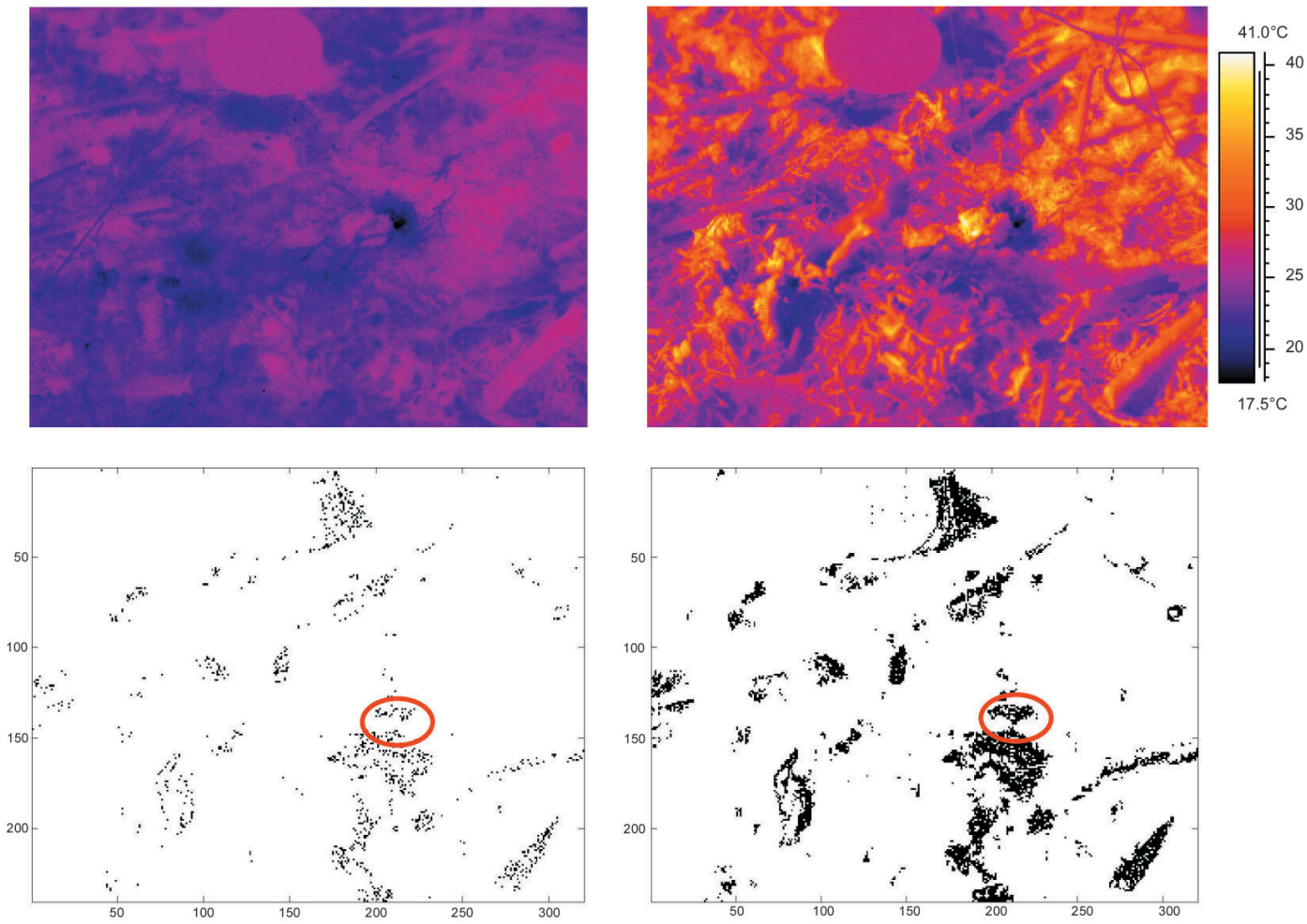

Fig. 11. Thermal images and temperature difference $\Delta T$ of mofette location in the forest of Podhorny Vrch, Czech Republic, recorded at two different times on 15th June 2003, at 18:18 h (scene shaded, top left) and at 18:26 h (scene sunlit, top right). Thresholds are set to $\Delta T<0.1 \mathrm{~K}$ (bottom left) $<0.5 \mathrm{~K}$ (bottom right). Red oval marks identified gas outlet.

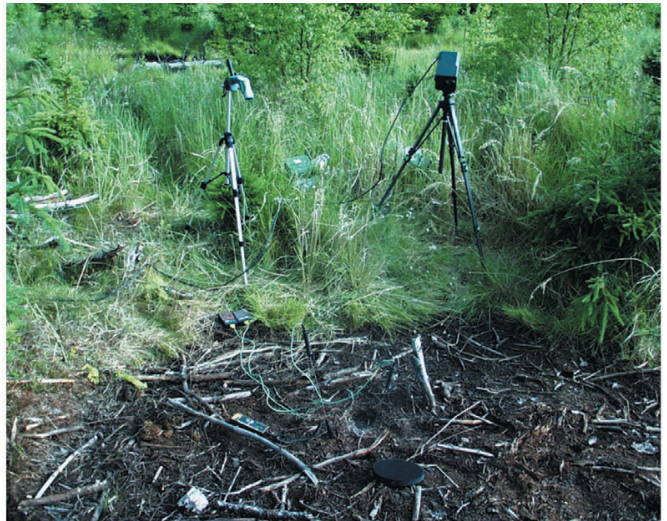

Fig. 12. Mofette location in forest of Podhorny Vrch, Czech Republic. when it was sunlit. The scale in fig. 11 top reveals that in the shaded scene temperatures are below $28^{\circ} \mathrm{C}$, when exposed to sunlight they go up to $40^{\circ} \mathrm{C}$. The images also show that the temperature increase is restricted to certain areas whereas others seem to maintain the temperature. This is confirmed through the results of the change rate detection procedure as the bottom pictures of fig. 11 show. A significant fraction of the area changes its temperature less than 0.1 and $0.5^{\circ} \mathrm{C}$ respectively. This very first result must be seen as preliminary and requires indepth investigations to verify the cause of the low temperature increase in these regions. The change rate detection method was developed after the field measurement had been finished so to date only the red ovals mark the single veri- 
fied gas outlet, it was heard, the cool gas was felt and the twigs have the light grey colour.

\section{Requirements to apply airborne infrared imaging technology}

Finally the question to be investigated is under which conditions mofettes can be detected

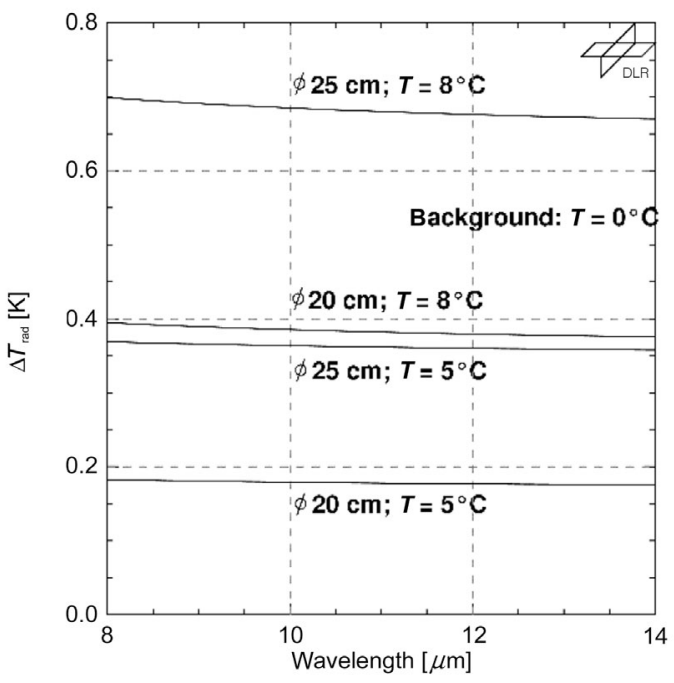

Fig. 13. Resulting temperature difference as function of percentage of warm area referred to the cold background picture element. by airborne infrared systems. The system on hand is an infrared multi-spectral line-scanner Daedalus AADS 1268. Besides channels in the visible and near infrared spectral bands it contains a channel in the 8-14 $\mu \mathrm{m}$ infrared band which is best suited to detect signatures at the temperatures prevailing at the West Bohemia mofettes. At a flight altitude of $300 \mathrm{~m}$ the spatial resolution on the ground results in picture elements sized about $70 \mathrm{~cm} \times 70 \mathrm{~cm}$.

The minimum detectable temperature difference, the noise equivalent temperature difference of the system is NE $\Delta T=0.15^{\circ} \mathrm{C}$. The favourable condition for detection is cold background soil and warm soil around the gas emanations as can be expected during winter in West Bohemia. Considering a background temperature of $0^{\circ} \mathrm{C}$ and a temperature of $5^{\circ} \mathrm{C}$, respectively $8^{\circ} \mathrm{C}$ for the gas release area the resulting $\Delta T$ for a picture element, has been calculated for two cases. In the first case the warm area covers $6.5 \%$ of the picture element in the second it covers $10 \%$ comparing to spots of $20 \mathrm{~cm}$ respectively 25 $\mathrm{cm}$ diameter. As can be seen from fig. 13 the small area is just at the detection limit whereas the larger one is well above for the lower temperature. For the higher temperature the conditions improve further.

Figure 14 shows a photo and a thermal image taken at Bublak, Czech Republic, on June 16, 2003 at 04:56 h a.m. The mofette is approximately $100 \mathrm{~cm}$ in length, $70 \mathrm{~cm}$ in width and about $80 \mathrm{~cm}$ deep. A fawn had fallen into it and
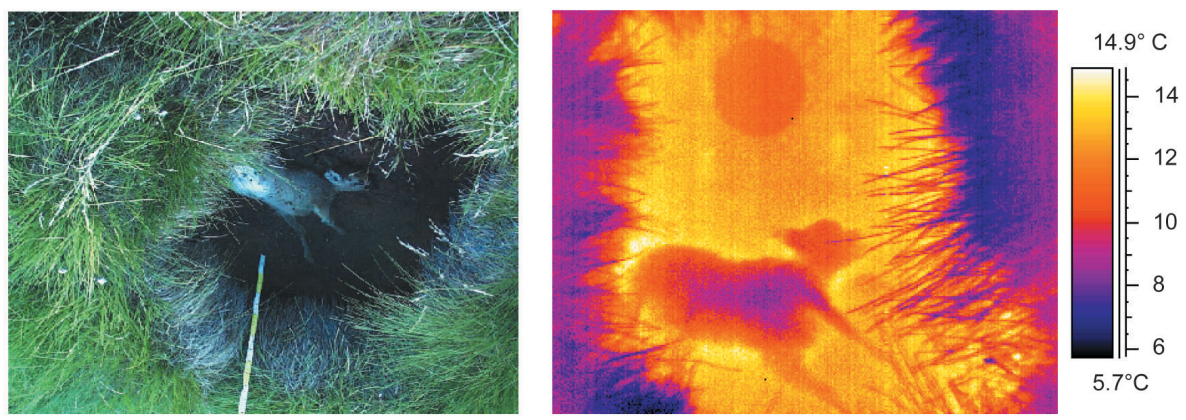

Fig. 14. Photo and thermal image of suffocated fawn in an approximately $80 \mathrm{~cm}$ deep mofette at Bublak, Czech Republic. The circular warm structure above the fawn is an infrared reference radiator that has not quite adapted the mofette soil temperature. 
suffocated. The soil is covered by rather short hard grass, inside the mofette there is no vegetation, the soil is wet. The soil temperature at the moffete ground is about $13^{\circ} \mathrm{C}$, of the grass around it about $7^{\circ} \mathrm{C}$. The air temperature is $8^{\circ} \mathrm{C}$. Such mofettes, which do not resemble the largest ones within this region, can easily be detected from the air. Certainly there are smaller ones. Sometimes the small ones are grouped in a smaller or larger area. Several small ones contributing to one pixel of the airborne scanner may thus be identified.

\section{Conclusions}

Gas emanations from mineral springs, water mofettes and dry mofettes spread over a wide area are of significant occurrence in the West Bohemia swarm earthquake region. Detection and mapping of as many of these as possible and consequent monitoring of their gas flux will aid an understanding of the geologic processes associated with the earthquake phenomenon. Because of the large area of interest and the often pathless terrain, airborne remote sensing demands consideration to perform the task. Of the three types of gas emanations dry mofettes are most likely to exhibit detectable thermal imprints caused by the gas. Hence infrared imaging techniques might be a method of choice.

Experiments were conducted to simulate soil/snow surface thermal anomalies caused by gas emissions of dry mofettes to investigate whether these can be detected by airborne infrared imaging systems. Via a metal lance a steady flow of compressed air was led about 20 $\mathrm{cm}$ deep into the soil of the test area, a lawn with short grass during summer experiments, which was snow covered during winter experiments. The gas seeped through the soil (and snow in winter) to the surface. A thermovision system was used to monitor the soil/snow surface temperature of the area being affected by the emanating gas as well as of the background not being affected. Thermal images were recorded under various environmental conditions. It was found that the emerging gas dampens surface temperature fluctuations which are caused by sunlight and weather and occur in the course of diurnal and seasonal changes. A «temperature change rate detection procedure» was applied to identify areas in the thermal images. It subtracts geometrical congruent images taken under different conditions. In the resulting images of temperature differences low differences indicate temperature dampened areas. A colour photo taken of the same scene aids in verification and elimination of areas dampened by other effects such as green vegetation, shadows, etc.

Finally estimations based on the experimental results indicate the feasibility to detect dry mofettes with an airborne infrared multi-spectral line-scanner Daedalus AADS 1268, such as that operated by the authors' institution. As the thermal contrast of the signatures is influenced by sun, wind and weather optimal detection conditions should be determined prior to flight measurements through systematic in situ ground investigations. Furthermore additional sensor systems like infrared array cameras and different platforms (aircraft, helicopter and airship) should be taken into account for the task.

\section{Acknowledgements}

The authors are grateful to E. Bankwitz, P. Bankwitz and H. Kämpf for many helpful discussions, instructions and hints.

\section{REFERENCES}

BAnkwitz, P., H. KÄMPf, M. StöRr and G. Schneider (2001): Shear faults in Tertiary clay formation of the Eger Basin (Czech Republic) and their role for the degassing of the uppermost mantle, Ber. Inst. Geol. Paläont. Univ. Graz, 4.

DE Jong, S.M. and TH.G. ChrIEN (1996): Mapping volcanic gas emissions in the Mammoth Mountain area using AVIRIS, in Summaries of the 6th Annual JPL Airborne Earth Science Workshop, AVIRIS Workshop, Jet Propulsion Laboratory, California Institute of Technology, Pasadena, CA, JPL Publ. 96-4, vol. 1, 75-82.

Koch, U., J. HeInICKE and M. Vossberg (2003): Hydrological effects of the latest Vogtland-NW Bohemian swarmquake period (August to December 2000), J. Geodyn., 35, 107-123.

Pfanz, H., D. Vodnik, C. Wittmenn, G. Aschan and A. RASCHI (2004): Plants and geothermal $\mathrm{CO}_{2}$ exhalations - Survival in and Adaptation to a high $\mathrm{CO}_{2}$ environment, Prog. Botany, 65, 499-538.

Weinlich, F.H., J. Tesar, S.M. Weise, K. BrÄUER and H. 
KÄMPF (1998): Gas flux distribution in mineral springs and tectonic structure in western Eger rift, J. Czech. Geol. Soc., 43, 91-110.

Weinlich, F.H., K. BräUer, H. KÄMPF, G. Strauch, J. Tesar and S.M. WeISE (1999): An active subcontinental mantle volatile system in the western Eger rift, Central Europe: gas flux, isotopic ( $\mathrm{He}, \mathrm{C}$ and $\mathrm{N}$ ) and compositional fingerprints, Geoch. Cosmoch. Acta, 63 (21), 3653-3671.
Weise, S.M., K. BRÄUER, H. KÄMPF, G. STRAUCH and U. KoCH (2001): Transport of mantle volatiles through the crust traced by seismically released fluids: a natural experiment in the earthquake swarm area Vogtland/NW Bohemia, Central Europe, Tectonophysics, 336, 137-150.

WolfE, W.L. and G.J. ZIssis (Editors) (1989): The Infrared Handbook (IRIA Center, ERIM - Environmental Research Institute of Michigan), pp. 1668. 